\title{
Usos y desusos del patrimonio cultural: retos para la inclusión social en la ciudad de México*
}

\author{
Ana Rosas Mantecón \\ Departamento de Antropologia, Universidad \\ Autónoma Metropolitana, México
}

RESUMEN: Quien arriba o no a los museos no ha sido objeto de una atención prioritaria por parte de éstos, generalmente concentrados en acrecentar, proteger y poner en escena sus acervos. El artículo analiza los factores que han impulsado el cambio de esta situación y que plantean nuevos retos a los museos, entre ellos el de atraer nuevos públicos y generar recursos, pero también el de reconceptualizar su función como instituciones incorporadas al desarrollo económico y cultural de la sociedad contemporánea. La autora muestra las potencialidades de los estudios de público para cumplir estos retos, basándose en el análisis de estadísticas de asistencia y exponiendo estudios cualitativos de públicos de patrimonio arquitectónico y de museos de la ciudad de México.

PAlABRAS Clave: Público de museos. Comunicación en museos. Museos. Patrimonio cultural. México.

RESUMO: As pessoas que chegam ou não aos museus não têm sido objeto de uma atenção prioritária por parte dessas instituições, geralmente ocupadas em acrescentar, proteger e colocar em cena seus acervos. Este artigo analisa os fatores que têm impulsionado mudanças nessa situação e que colocam novos desafios para os museus, dentre os quais, atrair novos públicos e gerar recursos; mas também, o de re-conceituar sua função como instituição participante do desenvolvimento econômico e social da sociedade contemporânea. A autora mostra o potencial dos estudos de públicos para superar os desafios colocados, baseandose em análises estatísticas de assistência e expondo estudos qualitativos dos públicos de patrimônio arquitetônico e de museus da Cidade do México.

PAlavras-Chave: Público de museus. Comunicação em museus. Museus. Patrimônio cultural. México.

ABSTRACT: Museum-goers or those who do not go have not been object of priority attention on the part of these institutions, usually occupied in adding, protecting and staging their collections.

\footnotetext{
* Versão final de texto apresentado na IV Semana dos Museus - Preservação em Museus: identidades, políticas, memórias, agosto de 2003, Universidade de São Paulo, São Paulo.
} 
1. Según Gonzalo AbadOrtíz, director de la Oficina de la UNESCO en México, se tienen registrados 200 mil sitios arqueológicos, 75 mil 22 monumentos históricos (de los siglos XVI al XIX), más un rico patrimonio mueble e inmueble de los siglos XX y XXI. De acuerdo al número de zonas de monumentos declaradas Patrimonio de la Humanidad, México ocupa el primer lugar de América y el sexto en el mundo (Reforma, Cultura, p. 1, 12 de mayo de 2003). Por lo que toca a número de ciudades declaradas patrimonio, ocupa el tercer lugar a nivel mundial, después de Italia y España.

2. Mientras el INEGI reconoce la existencia de 65 museos en la ciudad de México, el periódico $R e$ forma - que hizo recientemente una encuesta de sus públicos - habla de 200 , ya que incluye también en su recuento a las galerías. El reporte que me parece más confiable, elaborado por Ana Hortensia Castro en 2000 contabilizó 97 museos y pinacotecas. A nivel nacional, las cifras oscilan entre los 478 que reconoce el INEGI y 1000, según aseveró en 2002 Felipe Lacouture, especialista en museos y exdirector de ICOMOS-México. Las últimas cifras disponibles, del Atlas de Infraes tructura Cultural de México publicado en 2003 reconocen 1058 museos en el país y 127 en la ciudad de México.

3. Ana Hortensia Castro identificó los siguientes tipos de museos y pinacotecas en el Distrito Federal: antropología y arqueología (10), historia (19), arte (38), artes aplicadas (5), culturas populares (4), ciencia y tecnología (6), historia natural
This article analyses the factors that have driven changes in that situation and that pose the museums new challenges. Amongst these, the need to attract new publics and to generate resources, but, also, that of re-conceptualising its function as an institution participant in contemporary society's economic and social development. The author shows the potential of attendance studies in the overcoming of the challenges posed, based on attendance statistical analyses and expounds attendance qualitative studies regarding architectural patrimony and museums in Mexico City.

KEYWORDS: Museum attendance. Communication in museums. Museums. Cultural Patrimony. Mexico.

México es uno de los diez destinos turísticos más visitados del mundo y no cabe duda de que entre sus principales atractivos se cuenta su riqueza patrimonial', la cual ha sido reconocida por la UNESCO con más de una veintena de sitios declarados Patrimonio de la Humanidad. Los museos son una de las formas privilegiadas para poner en escena el patrimonio y la ciudad de México cuenta con $127^{2}$. Se trata de una cifra aproximada, ya que no existe un censo oficial al respecto, ni a nivel nacional ni metropolitano. En la mayor parte de los museos, los edificios que los albergan son también un valioso patrimonio artístico e histórico, por lo que junto con las colecciones configuran una parte significativa de la imagen que México proyecta hacia los extranjeros y también hacia los propios habitantes, dado que una alta proporción de los visitantes son mexicanos.

La mayor parte de los museos de la ciudad de México que tienen el carácter de nacionales, así como los de mayor importancia en términos de la diversidad, calidad y cantidad de sus acervos son manejados por el sector público (48). Las instituciones de educación superior operan también relevantes museos (15) e igual número son manejados por el sector privado. Agrupaciones religiosas y diversos fideicomisos controlan cada uno 4, las asociaciones civiles 10 y uno es producto de participación mixta (gubernamental y universitaria) (CASTRO, 2000, p. 21).

Como podemos observar en la gráfica siguiente, dentro de la distribución temática de los museos y pinacotecas dominan el arte, la historia, así como la antropología y la arqueología

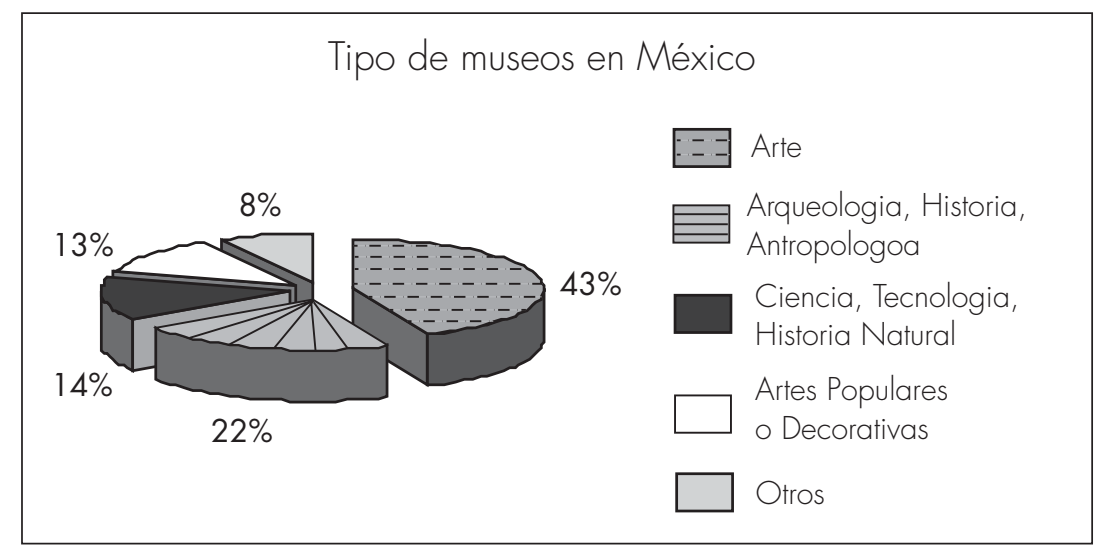


En el contexto latinoamericano, México es ciertamente uno de los países que dedica mayor presupuesto a la conservación del patrimonio y es notable el resultado en diversas áreas. Sin embargo, después de la crisis económica de los años ochenta, se han venido implementando políticas neoliberales que han recortado significativamente los presupuestos estatales para educación y cultura. A la reducción presupuestal se suma la presión para que las instituciones culturales y educativas alcancen niveles de eficiencia similares a los de empresas privadas. Importantes instituciones culturales, como los institutos nacionales de Bellas Artes, de Antropología e Historia (que manejan los principales museos en todo el país) se ven en la necesidad de imponer prácticas eficientistas que compensen la merma en sus presupuestos.

El resultado de estas políticas ha sido doble. En primer lugar, el Estado aminoró su presencia en el campo de la cultura, notoriamente la cinematográfica y la televisión pública, que sufrieron recortes presupuestarios de importancia. También lo hizo en el campo de los museos: a diferencia de lo que sucedía en las décadas de 1960 y 1970 cuando el 80 por ciento de los museos eran oficiales, ahora aproximadamente sólo un 15\% pertenecen a los institutos nacionales de Antropología e Historia y de Bellas Artes ${ }^{4}$. En segundo término, se fomentaron modos de gestión empresariales, con la participación de empresas privadas que vienen compitiendo con el Estado en la producción de bienes culturales. En el caso de los museos, la reducción paulatina de los recursos para la operación, conservación y restauración de sus colecciones, investigación y difusión de sus acervos, ha colocado a buena parte de ellos en una situación crítica para operar de manera óptima y sobre todo, para continuar su crecimiento y seguirle el paso a la transformación acelerada del entorno en el que se encuentran.

Los museos y la ciudad interminable

En la ciudad de México los grandes momentos de desarrollo de la infraestructura cultural ocurrieron entre los años veinte y los sesenta del siglo XX: se construyó una gran cantidad de instalaciones educativas y culturales, entre ellas museos, teatros y cines, alentando las artes para el fortalecimiento de la identidad nacional. A partir de los años ochenta la reducción de los presupuestos públicos limitó la expansión de la infraestructura, perdiéndole el paso a una urbe que no paraba de crecer.

Al igual que ocurre con la mayoría de la infraestructura cultural de la ciudad de México - con excepción ahora de los cines -, los museos se encuentran fuertemente centralizados: tan sólo cuatro delegaciones concentran el 87,6\% del equipamiento museológico, y cinco de éstas no cuenta con ninguno. Podemos aquilatar la distancia geográfica que los separa de la mayoría de la población si tomamos en cuenta que esas cuatro delegaciones centrales ocupan el mismo espacio con el que contaba la ciudad de México a principios del siglo XX y que
(6), comunitarios (2), otros (7).

4.Así lo declaró Felipe Lacouture al diario Refor$m a$, Cultura, p. 1, 18 septiembre 2002. 
en la actualidad se extiende a 1.500 kilómetros cuadrados de territorio conurbado, que pasó de 3,1 millones de habitantes en 1950 a 18, 1 en la actualidad. Más que ante una metrópolis nos hallamos frente a una megalópolis, si tomamos este concepto para designar una etapa en la que una gran concentración urbana se entreteje con otras ciudades y zonas rurales, configurando una red de asentamientos interconectados (MESSMACHER, 1987, p. 16-17). Pero no es un caso aislado. También espectacular ha sido el crecimiento de São Paulo, que hace apenas cien años albergaba una población de 265 mil habitantes y que hoy día es similar a la mexicana, lo que ha llevado a ambas ciudades a contarse entre las cinco más grandes del planeta, al lado de Tokio, Nueva York y Bombay. En realidad, diversas ciudades en el mundo han crecido cada vez más rápido. Mientras en 1950 sólo Nueva York albergaba más de diez millones de habitantes, en 1995 había 14 megalópolis que habían rebasado ese número de habitantes y para el 2000 lo alcanzaron 17 (United Nations Population Division, citada en ZWINGLE, 2002, p. 72-73). Si bien es cierto que parte de ese aumento de población ha ocurrido en el mundo industrializado, las estadísticas internacionales auguran que casi todo el crecimiento demográfico del mundo en los próximos treinta años tendrá lugar en ciudades de países en desarrollo, planteando nuevos retos a la relación de los museos con el territorio circundante.

En la ciudad de México los museos van quedando geográficamente rezagados frente al vertiginoso crecimiento urbano. Dado que éste no fue producto de una cuidadosa planificación, no se acompañó por una expansión descentralizada de los servicios básicos y de la oferta cultural, de manera que el acceso a los mismos se ha dificultado para la mayoría de la población que reside lejos del centro. Pero entre los museos y sus públicos potenciales se tienden no sólo kilómetros de distancia, sino también otras barreras que ha traído consigo el caótico desarrollo urbano, como el congestionamiento vehicular, la violencia, el comercio informal en las calles, que junto con el mayor peso de los medios como la televisión y la radio en el tiempo libre de los habitantes, favorecen la desarticulación de muchos espacios tradicionales de encuentro colectivo y alimentan una creciente segregación social y espacial.

\section{En busca del público desconocido}

La fuerza adquirida por las industrias culturales y la comunicación masiva de la cultura a domicilio reduce comparativamente el peso del patrimonio histórico y artístico: mientras los museos más concurridos atraen a un millón y cuarto de visitantes por año, estas cifras son superadas diariamente por las audiencias de radio y televisión: más del $80 \%$ de la población de la ciudad de México escucha regularmente la radio durante los días laborales y el $90 \%$ encuentra en el ver televisión la principal actividad de su tiempo libre, según nos reportan las encuestas elaboradas por el diario Reforma. Según el mismo sondeo, 
en el 2000 un 62\% de los entrevistados respondió que nunca asistía a museos y $32 \%$ sólo lo hacía rara vez, en el $2001^{5}$.

En realidad, nuestro desconocimiento sobre los museos es similar al que tenemos sobre sus públicos, tanto en términos cuantitativos como respecto a cómo se relacionan con las ofertas museográficas, sus expectativas y demandas. En México no existe un ordenamiento sistemático y comparativo de las estadísticas culturales, ni algún organismo dedicado al estudio de este campo. El Instituto Nacional de Estadística, Geografía e Informática (INEGI) da una atención secundaria a la información cultural, y sus cifras son demasiado generales, imprecisas y de difícil comparación de un año a otro. El único esfuerzo por generar información diacrónica que permita analizar las transformaciones de los campos culturales es el realizado anualmente por el periódico Reforma desde 1994, pero no ha dado una atención específica a los museos, sino hasta este año.

Esta situación empieza a cambiar lentamente. El estudio del consumo cultural en México ha vivido un desarrollo vertiginoso en la última década, fundamentalmente porque ha sido estimulado desde disciplinas y ámbitos diversos y por una gama amplia de demandas, que abarcan desde la búsqueda de democratización de las políticas culturales hasta la mejor mercantilización de las industrias culturales. En su introducción a El consumo cultural en México, un texto que fue fundacional para esta área de estudios a principios de los años noventa, se preguntaba Néstor García Canclini cómo era posible que en un país como México donde, al menos desde los gobiernos posrevolucionarios, se manifiesta una intensa preocupación por extender los vínculos del arte y la cultura hacia las masas, no se hicieran investigaciones sobre públicos, consumo y recepción de bienes culturales (CANCLINI, 1993). Considero que, fundamentalmente, porque el diseño e implementación de las políticas culturales se desenvolvió a lo largo del siglo en un contexto antidemocrático que consideraba innecesarias las evaluaciones sobre su relación con las necesidades y demandas de los públicos. Con contadas excepciones, las instituciones oficiales carecían de diagnósticos que les permitieran formular, evaluar y reorientar sus políticas.

La primera investigación sobre público de museos - pionera en América Latina - fue realizada por Arturo Monzón en el Nacional de Antropología, allá por los años cincuenta. Los escasos estudios de los años setenta y ochenta no tuvieron continuidad ni contagiaron inmediatamente a otras áreas de la cultura. Dentro de estas investigaciones se encuentran la dirigida por Rita Eder sobre "El público de arte en México: los espectadores de la exposición Hammer" y la coordinada por Néstor García Canclini, El público como propuesta: cuatro estudios sociológicos en museos de arte (CIMET et al., 1987).

Pero la sociedad mexicana se ha ido transformando y resultaba imposible que la efervescencia de las demandas sociales y políticas que pugnaban por una mayor democratización, notoria desde finales de los años sesenta, dejaran intocadas a las instituciones culturales. Ya en los noventa, la ciudad de México comenzó a elegir a sus gobernantes y se multiplicaron las asociaciones civiles que representan a sectores antes marginados del sistema político. Las instituciones gubernamentales se vieron cuestionadas y comenzaron los sondeos
5. Encuesta sobre Consumo Cultural y Medios, Reforma, 12 de abril de 2002, (http://www.reforma.com). 
6. Reforma, Cultura, p. 1, 14 mayo 2003 sobre los destinatarios de sus acciones. Partiendo de que una política cultural democrática requiere superar las formulaciones dirigistas y vincular orientaciones globales con demandas reales de la población, los estudios de consumo se veían como necesarios tanto para la adecuada formulación de políticas culturales como para su evaluación.

Mas no fueron solamente las crecientes demandas de la sociedad civil las que movieron a buscar conocer mejor a sus destinatarios a las instituciones gubernamentales. Como ya mencioné, los fondos cada vez más raquíticos con los que operan, las presiones económicas y las nuevas lógicas mercantilistas que se les imponen, han empujado a diversas instituciones a buscar conocer mejor la información sobre su audiencia real y potencial. Durante los años ochenta un número creciente de instituciones culturales desarrollaron sus propias fuentes de financiamiento tales como cuotas de admisión, tiendas, donaciones no gubernamentales, etc., ante la insuficiencia de los financiamientos públicos. Respecto a estas transformaciones en el campo de los museos, se pregunta Graciela Schmilchuk:

¿Es la proliferación inaudita de museos y exposiciones en el mundo, compitiendo entre sí y con otras ofertas culturales? ¿ $\mathrm{O}$ es quizás el debilitamiento y empobrecimiento de los Estados protectores y de las instituciones tradicionalmente patrocinadoras lo que lanza a los museos a buscar un impacto y unos beneficios consensuales y legitimadores que antes no buscaban para ubsistir? (SCHMILCHUK, 1996).

No obstante las presiones, esta búsqueda no se ha traducido en los museos mexicanos en un desarrollo sistemático de investigaciones de público. La mayor parte de estas instituciones en la ciudad de México no ha estudiado los perfiles y necesidades de sus visitantes, situación que dificulta el diseño de estrategias comunicativas para una interacción y participación eficaz con ellos: los estudios de público son escasos, en siete museos se han realizado esporádicamente y sólo dos tienen un equipo profesional para desarrollarlos sistemáticamente (CASTRO, 2000, p. 33). Así lo ha reconocido Graciela de la Torre, directora del Museo Nacional de Arte: "En los museos mexicanos, el público suele ser marginado pues por lo general muchas de las opiniones se toman desde el escritorio"6. Además, los sondeos sobre los visitantes no se traducen en un mayor conocimiento público de las evoluciones de las audiencias, ya que no son dados a conocer más que ocasionalmente, por lo que no resultan acumulativos ni de fácil acceso, como para contribuir a evaluar globalmente las políticas culturales.

Los principales espacios en los cuales se realizan estudios de consumo cultural en México son las universidades y otros centros de investigación. Parte del impulso al desarrollo de las investigaciones en esta área se ha dado por los recursos provenientes de instituciones culturales gubernamentales y por la incursión ocasional de algunos investigadores en estudios para industrias culturales, pero han sido fundamentalmente dinámicas propias de los ámbitos académicos alimentadas por las discusiones internacionales, los exilios latinoamericanos así 
como por el diálogo con las demandas sociales -, las que han tenido una mayor relevancia para el rumbo que han tomado las indagaciones sobre audiencias ${ }^{7}$.

La certeza sobre cuántos visitantes acuden a los museos sigue aún pendiente. No obstante que las cifras oficiales nos muestran un incremento constante tanto de museos como de visitantes en la última década - como puede apreciarse en el siguiente cuadro - hay visiones menos optimistas, como la del investigador Felipe Lacouture, quien considera que son sólo unos 15 ó 17 millones de personas - alrededor del 16\% de los poco más de 97 millones que habitan en el país - los que visitan anualmente los museos en México, mientras que en Alemania y en Francia el $40 \%$ y el 33\% de la población, respectivamente, asiste año con año a esos recintos ${ }^{8}$. Otro contraste lo representa el Museo del Aire y el Espacio de Washington, que recibe a casi diez millones de visitantes al año (WITKER, 2001, p. 9).

Museos y visitantes en México según origen

\begin{tabular}{lcccc}
\hline Año & Museus & Total de visitantes & Nacionales & Extranjeros \\
\hline 1992 & 182 & 14.291 .493 & 11.989 .979 & 2.301 .514 \\
\hline 1993 & 215 & 15.601 .762 & 13.278 .012 & 2.323 .750 \\
\hline 1994 & 325 & 19.004 .189 & 16.992 .901 & 2.011 .288 \\
\hline 1995 & 348 & 22.039 .831 & 20.085 .238 & 1.954 .593 \\
\hline 1996 & 381 & 26.548 .143 & 24.532 .727 & 2.015 .416 \\
\hline 1997 & 398 & 34.682 .549 & 31.675 .841 & 3.006 .708 \\
\hline 1998 & 412 & 37.308 .078 & 33.352 .561 & 3.955 .517 \\
\hline 1999 & 444 & 39.874 .379 & 35.623 .659 & 4.250 .720 \\
\hline 2000 & 429 & 36.933 .056 & 33.706 .218 & 3.226 .838 \\
\hline 2001 & 478 & 39.376 .606 & 35.420 .023 & 3.956 .583 \\
\hline
\end{tabular}

Nota: Incluye la información de los museos identificados en zonas arqueológicas. No incluye museos comunitarios y salas museográficas ubicadas en otras instalaciones culturales como escuelas, parques, etcétera.

Fuentes: INEGI e Instituto Nacional de Antropología e Historia.

La primera encuesta que sondeó las prácticas de consumo cultural en la ciudad de México, en 1989, mostró una baja asistencia a los museos: sólo cuatro habían sido visitados alguna vez por más del 5\% de la población: el Museo Nacional de Antropología, el de Cera, el del Templo Mayor y el de Historia Natural (CANCLINI; PICCINI, 1993, p. 50). De acuerdo al INEGI, entre 1995 y 1997 los visitantes de museos en la ciudad de México ascendieron en promedio cada año a 6.041.015 15.617.635 nacionales y 423.380
7. Para un balance sobre los estudios de consumo cultural en México puede consultarse MANTECÓN, 2002.

8. Reforma, Cultura, p. 1, 18 septiembre 2002 . 
9. En el Bosque de Chapultepec se encuentra la mayor área verde de la ciudad así como una importante concentración de museos con una oferta diversificada, que va desde el Museo Nacional de Antropología (punto de referencia obligado para el turismo) hasta el Museo del Papalote para niños, y también comprende los museos de Historia Natural, elTecnológico, el de Arte Moderno y el de Arte Contemporáneo Rufino Tamayo. Ahí se encuentra el zoológico, que recibe 5.5 millones de visitantes al año.Ver www.zoologicodechapultepec.com. Por otra parte, resulta ilustrativa la comparación de visitantes atraídos a nive nacional por museos zoológicos, según los datos del INEGI en 2001 mientras el promedio diario de visitantes a museos fue entonces de 173, el correspondiente a los zoológicos fue de 1897. Algunas zonas arqueológicas tienen un gran atractivo para diversos sectores: a Teotihuacan llegan unos cinco millones de visitantes al año (WITKER, 2001, p. 41)

10. Fuentes: 1995-2000 Coordinación de Asesores de Ignacio Toscano 2001 INAH y 2002 periódico Reforma. La cifra de Museo Nacional de Antropología proviene de Atlas de Infraestructura Cultural de México, p.142.

11. En 1999, los museos del país recibieron 4.250.720 visitantes extranjeros, y un año después sólo 3.226.838. extranieros). En el 2001 la cifra total fue de 16.493.159 triplicándose los visitantes nacionales (15.605.302) y duplicándose los extranjeros (887.857).

Si revisamos las pocas cifras disponibles por museo, encontramos que mientras algunos han incrementado sus públicos, otros los han visto disminuir. Así, mientras entre 1995 y 2000, el Museo Nacional de Arte recibió 129.071 visitantes en promedio al año, en el 2002, después de una profunda reestructuración, la cifra de concurrentes casi se duplicó (240.000). Aún en un lapso menor de tiempo, el Museo Nacional de Antropología (sin duda, el más visitado de todo el país) atrajo en 2001 a 1.170 .948 visitantes y en 2002 a 1.250.000, una cifra ciertamente relevante pero que constituye poco más de la cuarta parte de los que acudieron al Zoológico de Chapultepec ese mismo año, que se ubica enfrente?. No ocurrió lo mismo a los museos Mural Diego Rivera y Carrillo Gil, que vieron disminuir sus concurrentes entre 1995 y 2002 (de 97.220 a 96.000 el primero, y de 71.044 a 36.000 el segundo) ${ }^{10}$.

Decía al comenzar este trabajo que los museos son parte de la imagen que México proyecta hacia los extranjeros. Sin embargo, son contados los que efectivamente cumplen ese papel: Nacional de Antropología, Templo Mayor, Palacio de Bellas Artes, de Arte Moderno y Frida Kahlo reciben un alto porcentaje de turistas provenientes de otros países, pero en los demás su presencia no es significativa (CASTRO, 2000, p. 15). En el año 2000 llegaron a México 20,6 millones de turistas internacionales, de los cuales la ciudad de México recibió 2, 1 millones. En ese mismo año, de acuerdo al INEGI, sólo el 15\% de los turistas extranieros que arribaron visitó los museos en el país (la cifra de visitantes era menor a la del año anterior)" y el $40 \%$ de los que lo hicieron a la ciudad capital acudió a dichos recintos. En lo que toca a los visitantes a las zonas arqueológicas del país durante el 2000, la proporción de visitantes extranjeros es mayor: la tercera parte de los 9,47 millones que recibieron eran turistas provenientes de otros países. Sin embargo, el número de dichos visitantes era muy similar al de un año anterior y disminuyó de 3.199.400 en 2000 a 2.641.400 un año más tarde.

Barreras entre los museos y sus públicos. Dos estudios de caso

¿Quiénes logran llegar a los museos? Aquellos que sortean exitosamente las barreras que dificultan el acceso: los que logran desplazarse y vencer la distribución concentrada e inequitativa de los equipamientos culturales, aquellos que actúan a contracorriente de la tendencia internacional hacia la disminución de la asistencia a espectáculos urbanos, en tanto crece el consumo a través de aparatos de comunicación masiva en el ámbito familiar y aumenta la inseguridad en las calles; los que pueden pagar el precio de entrada, que en el caso de los museos de la ciudad oscila entre 30 y 35 pesos (aproximadamente 3 dólares, que equivalen a un día de salario mínimo de una población que ha visto disminuir agudamente su poder adquisitivo desde la crisis económica de los años ochenta), pero que puede no ser un obstáculo si se considera que todos 
los recintos tienen entrada libre a estudiantes y maestros con credencial, a niños menores de 12 años y adultos mayores de 60 y a todo público un día a la semana.

Sabemos que el mercado potencial de la oferta cultural no sólo es cuestión de precio, sino también de contar con las disposiciones incorporadas y adecuadas para poder distinguir, evaluar y disfrutar las prácticas y productos culturales. En la bibliografía internacional sobre consumo cultural se explican su desarrollo y desigualdades según la accesibilidad de los equipamientos, la disponibilidad de recursos económicos, los hábitos culturales previos y la estructuración del tiempo libre en diferentes sectores de la población. A todas estas condiciones las distingue la aguda desigualdad con que se distribuyen entre los habitantes de la ciudad de México. La combinación de estos obstáculos, la forma en que se potencian unos a otros, genera procesos de segregación cultural y de escaso aprovechamiento de muchos de los servicios culturales existentes.

Acceden entonces a la oferta cultural los que tienen el capital cultural y/o pueden pagar por su disfrute como espectadores y, en el mejor de los casos, los que se sienten convidados; quedan excluidos todos aquellos que no saben, que no han oído - en la escuela o en los medios - que el disfrute de los bienes y los servicios culturales es indispensable para lograr una mejor calidad de vida (AURA, 1999) y que constituyen los no-públicos de la cultura. Las posibilidades de que estos no-públicos se acerquen a los museos se ven limitadas, por otra parte, por las propias comunidades a las cuales pertenecen. Si reconocemos que el consumo no es algo "privado, atomizado y pasivo", sino "eminentemente social, correlativo y activo", no un "artefacto de los caprichos o necesidades individuales" sino "un impulso socialmente regulado y generado" (APPADURAI, 1991, p. 48-491, entenderemos el desinterés de ciertos sectores en los museos; éste no se debe sólo al débil capital simbólico con que cuentan para apreciar esos mensajes sino también a la fidelidad a los grupos en los que se insertan. Dentro de la ciudad, son sus contextos familiares, de barrio y de trabajo los que controlan la homogeneidad del consumo, las desviaciones en los gustos y en los gastos (CANCLINI, 1995, p. 49).

Todas estas disposiciones son las que hacen que se construya un público cuando se logra reducir la distancia social percibida que les separa de aquellos productos y prácticas. En una encuesta aplicada en todo el país a principios de los años noventa, trascendió que la mayoría de la gente percibe "cercana" a su vida y experiencia urbana los templos (campo religioso), las escuelas (campo educativo) y las clínicas (campo de la salud). A medida que se avanza hacia recintos más cargados del sentido social construidos para el arte, mayor es la distancia de la percepción. Mientras más se acerca al núcleo del equipamiento del campo artístico (salas de concierto, galerías y cines de arte) menor es la cantidad de personas que los percibe, ya no digamos, ni siquiera lejanas. Ello deja fuera por completo de la experiencia artística a una parte enorme de la población. 
Uso del equipamiento cultural público en México

Nunca ha estado (1993)

\begin{tabular}{lc}
\hline Equipamiento & Total \\
\hline Cine & $22,8 \%$ \\
\hline Museo & $36,4 \%$ \\
\hline Biblioteca pública & $41,5 \%$ \\
\hline Teatro & $46,5 \%$ \\
\hline Casa de la cultura & $51,1 \%$ \\
\hline Auditorio & $51,9 \%$ \\
\hline Sala de conciertos & $62,1 \%$ \\
\hline Cine de arte & $66,6 \%$ \\
\hline Galería de arte & $67,6 \%$ \\
\hline
\end{tabular}

Fuente: s Formación de Ofertas Culturales y Públicos, (GONZÁlEZ; CHÁVEZ, 1996).

Se trata de una distancia social que jamás les permitirá no sólo entrar en ellos sino siquiera percibirlos como parte de su experiencia cotidiana posible (GONZÁLEZ; CHÁVEZ, 1996, p. 45-46). Esa distancia social tiene una clara marca de clase, como se puede apreciar en el siguiente cuadro.

Recintos culturales en los que ha estado, según nivel socioeconómico en México (1993)

\begin{tabular}{llccc}
\hline & Total & Alto & Medio & Bajo \\
\hline Museo & $46,3 \%$ & $61,7 \%$ & $48,4 \%$ & $42,5 \%$ \\
\hline Casa de la cultura & $32,6 \%$ & $45,3 \%$ & $36,0 \%$ & $28,3 \%$ \\
\hline Biblioteca pública & $38,4 \%$ & $44,6 \%$ & $39,6 \%$ & $36,8 \%$ \\
\hline Sala de conciertos & $22,8 \%$ & $36,5 \%$ & $24,7 \%$ & $19,5 \%$ \\
\hline Auditorio & $32,3 \%$ & $42,2 \%$ & $34,1 \%$ & $29,6 \%$ \\
\hline Cine de arte & $17,5 \%$ & $32,2 \%$ & $19,6 \%$ & $13,9 \%$ \\
\hline Galería de arte & $17,6 \%$ & $34,7 \%$ & $18,6 \%$ & $14,5 \%$ \\
\hline
\end{tabular}

Fuente: Proyecto Formación de Ofertas Culturales y Públicos (GONZÁLEZ; CHÁVEZ, 1996). 
Hay otro tipo de barreras que dificultan a los habitantes de la ciudad el gozar de las ofertas culturales, entre ellas la arquitectura y la imagen urbana, y que expondré a través de un estudio de caso sobre las representaciones del patrimonio en el Centro Histórico ${ }^{12}$. Me refiero a la monumentalización y sacralización del patrimonio, que les impiden reconocerse colectivamente en él, así como participar de manera activa en las políticas referidas a su entorno.

Primer estudio de caso: La sacralización como obstáculo. Los no-públicos del patrimonio del Centro Histórico de la ciudad de México

La mayor concentración de monumentos prehispánicos y coloniales, no sólo de México sino de América Latina, la encontramos en el Centro Histórico de la ciudad de México: además de restos arqueológicos y edificaciones históricas, varios de los principales museos de arte e historia, teatros, cines, parques y plazas. Se trata de un territorio que condensa seis siglos de historia urbana y que, no obstante la multiplicación de numerosos subcentros en la ciudad capital, continúa siendo el punto de referencia simbólico y político por excelencia. Su historia ha sido la de vastas construcciones que vieron transcurrir por ellas a ricos habitantes, que cedieron el paso a inquilinos menos afortunados que vienen siendo progresivamente expulsados hacia tugurios periféricos por la expansión de las actividades de comercio y servicios.

No obstante la cercanía geográfica, los habitantes del Centro Histórico se encuentran lejos, simbólicamente, de dicha oferta. De ahí el bajo uso que realizan del equipamiento y de la oferta cultural. La inequidad en el acceso a la cultura se manifiesta así no sólo en la concentración de los circuitos de distribución de la oferta cultural y los principales equipamientos, sino también en la desigualdad en cuanto a la formación artística y cultural que les impide a estos sectores imaginarse siquiera como consumidores potenciales de la muy grande oferta cultural de la zona.

Si bien a nivel mundial ha ido en aumento el consenso en torno a la ampliación del concepto de patrimonio cultural, para que comprenda no sólo lo producido en el pasado sino también bienes culturales actuales, no sólo lo tangible (como los monumentos arquitectónicos) sino también lo intangible (como las tradiciones y las lenguas), y no sólo los bienes producidos por las élites sino también lo popular. En realidad, encontramos que la extensión de la definición de patrimonio no se ha correspondido ni con la legislación ni con las políticas de conservación. Así como el patrimonio intangible recibe considerablemente menos apoyo que el tangible, el popular se encuentra en desventaja frente a otras producciones culturales que gozan de mayor legitimidad. Las jerarquías en la aplicación presupuestal han sido señaladas en múltiples ocasiones.

En el mismo sentido, las políticas estatales de protección de monumentos han estado regidas en general por criterios monumentalistas. Para
12. El estudio de este proceso se desarrolló a través de revisión documental, encuestas y entrevistas en profundidad a los nuevos propietarios de los inmuebles rehabilitados en el Centro Histórico tras los sismos de 1985. Ver MANTECÓN, 1998. 
13. No obstante su limitado rango de acción (apenas el $9 \%$ de los monumentos que se utilizan como vivienda), se restauró un mayor número de inmuebles que los intervenidos en varias décadas de vigencia de las leyes y decretos de protección al Centro Histórico (RHP, 1988) empezar, no hay un acuerdo entre las instituciones involucradas en la conservación del patrimonio en torno al número y tipo de monumentos que deben ser conservados. Al delimitarse de manera oficial el Centro Histórico, en el decreto se incluyó una lista de edificios que se consideraron como monumentos históricos, fundamentalmente por su valor y relevancia arquitectónica. Sin embargo, gran cantidad de edificaciones utilizadas como viviendas no aparecían en esa lista, sobre todo por el criterio monumentalista con el que fue elaborada, el cual desdeña las muestras de arquitectura popular que desde otro punto de vista podrían ser consideradas parte del patrimonio del Centro Histórico, aun en el caso de las que no son evidencias únicas pero que se integran adecuadamente al conjunto arquitectónico y le dan su carácter peculiar a calles y barrios. En la búsqueda de legitimación a través de la utilización de determinados espacios (como ocurrió en los casos del Zócalo y del Templo Mayor, que analizaré enseguida), el Estado ha sacralizado funciones y jerarquías que, por otra parte, le han permitido legitimar o excluir otros usos. Una y otra vez se ha hecho patente el desprecio por la conservación de los inmuebles históricos o artísticos con función de vivienda. Pasaron sobre ellos la apertura y prolongación de calles (como la del Paseo de la Reforma en los años sesenta), la construcción de conjuntos de multifamiliares (como el de Tlatelolco), y aún en coyunturas especialmente favorables para la rehabilitación, como fue la postsísmica, fueron desatendidos en su mayoría ${ }^{13}$.

La jerarquía simbólica del patrimonio que, como mostré, subyace a las políticas de definición y conservación de monumentos, es compartida por diferentes sectores sociales. El Centro Histórico es apreciado por el conjunto de la población como un espacio emblemático pero, si bien es innegable esta valoración positiva general del conjunto monumental, una mirada más atenta nos permite vislumbrar que en ese conjunto reconocido no se incluye de la misma manera a todo el patrimonio: tiende a valorarse más lo prehispánico que lo colonial, lo arquitectónico que lo intangible, lo monumental que lo popular.

Si atendemos a lo que dijeron los entrevistados - habitantes de vecindades rehabilitadas tras los sismos de 1985 - sobre los espacios del Centro Histórico que se mostrarían a un visitante, el Zócalo es sin lugar a dudas el más importante. Constituye un espacio fundamental para mostrarnos pero también para reconocernos. Así, ante la pregunta de a qué lugares llevaría a pasear a sus hijos, también el Zócalo fue la opción más socorrida para una cuarta parte de los entrevistados.

No ocurre lo mismo con otros exponentes de nuestro patrimonio, como el Palacio de Bellas Artes, que pareciera constituir un espacio que funciona para mostrarnos orgullosamente hacia el exterior pero no como ámbito deseado de socialización que forme parte del mundo cotidiano. Mientras el 7,6\% llevaría a un visitante a Bellas Artes, tan sólo el 1,5\% considera relevante que sus hijos lo conozcan. Por su parte, la Alameda Central - el mayor parque de la zona goza de las mayores simpatías como espacio de recreación familiar para poco 
más de la quinta parte de los encuestados, mientras apenas el 4,7\% llevaría allí a un visitante. Su carácter cotidiano, al igual que el del Zócalo, fue ampliamente mostrado cuando los interrogamos sobre los mejores y los peores lugares para pasear, y ambos espacios fueron seleccionadas como los más atractivos.

Podría formular la hipótesis de que el patrimonio monumental, constituído por aquellas obras únicas cuya relevancia arquitectónica o histórica cuenta con amplio consenso, tiene como función estructurar la imagen urbana en el centro de la ciudad, más que servir como un equipamiento cuyo uso sea frecuente; por tanto, su papel podría valorarse como más emblemático que cotidiano. Así, al mostrarles un conjunto de fotografías de espacios característicos de la zona central, de manera general un 66,4\% no los había visitado en el último año. Bellas Artes fue reconocido prácticamente por todos los entrevistados, pero sólo un mínimo porcentaje lo había visitado alguna vez.

La no cotidianeidad de los habitantes de vecindades rehabilitadas en su relación con los monumentos se vincula estrechamente a la sacralización de que son objeto, así como a la asociación entre patrimonio y funciones educativas y culturales. Ante la posibilidad de que se permitiera el uso de pirámides o iglesias para diversas actividades, un 77\% (en promedio) se manifestó en contra; el único uso medianamente tolerado fue la realización de conciertos de música clásica, considerada como legítima, ya que pertenece, junto con ciertas obras monumentales, a la alta cultura. Es curioso, si lo contrastamos con el rock, que despertó el doble de oposición.

Opinión sobre el uso de pirámides o iglesias para:

\begin{tabular}{lccc}
\hline & A favor & Le da igual & En contra \\
\hline Rock & 16,8 & 3,4 & 79,8 \\
\hline Fiestas & 13,9 & 2,1 & 84,0 \\
\hline Música clásica & 46,6 & 4,2 & 48,7 \\
\hline Concursos de belleza & 16,4 & 2,1 & 81,5 \\
\hline Comerciales & 36,6 & 3,4 & 60,1 \\
\hline Recepciones Oficiales & 25,2 & 3,8 & 71,0 \\
\hline
\end{tabular}

Fuente: Encuesta a habitantes de vecindades rehabilitadas tras los sismos de 1985 (MANTECÓN, 1998).

La pregunta sobre el uso deseable de un convento rehabilitado nos permite mostrar más claramente el distanciamiento y la reverencia hacia los monumentos. Frente a las opciones con mayor porcentaje de aceptación, como las de convertirlo en museo (36\%), escuela (31\%) y biblioteca (12\%), es destacable 
14. Su denominación viene del proyecto decimonónico de adornar la plaza principal con un monumento a la Independencia el cual quedó in concluso: sólo se levantó el basamento o zócalo sobre el cual iba a erigirse. el bajo porcentaje que consideró usos menos sacralizados y más cotidianos como vivienda (3\%), hospital $(7 \%)$, gimnasio (1\%) u oficina $(0,8 \%)$. Se presenta una asociación entre monumento y, por lo tanto, pasado, con un uso educativo y/o escolarizado. El problema con el distanciamiento de que es objeto el patrimonio es que obstruye las posibilidades de que sea apropiado como referente identitario y como espacio para el disfrute y el enriquecimiento cultural. Extraña paradoja: la gente que vive en el espacio donde se concentran con mayor intensidad las expresiones del patrimonio no puede apropiarse de ellas. En mayor o menor medida le son ajenas.

La sacralización y monumentalización del patrimonio imponen barreras para que la población pueda apropiárselos en su vida cotidiana y están en la base de procesos de exclusión social, como el que durante décadas reservó el Zócalo para los rituales políticos del partido dominante. El Zócalo ${ }^{14}$ es el nombre popular de la plaza principal del centro de la ciudad de México. Fue durante varios siglos un espacio pleno de vida comercial, política, religiosa, propicio para la recreación y la sociabilidad de los habitantes de la urbe. Desde mediados del siglo XIX el poder gubernamental inició un largo proceso de apropiación: paulatinamente se fue haciendo desaparecer cualquier rastro de actividades que no fueran las ceremoniales: se quitaron jardines, bancas y fuentes, se expulsaron tranvías y comerciantes populares, para dejar sólo una plataforma de cemento vacía y una bandera al centro, flanqueada por edificios que encarnan el poder de la Iglesia y el Estado, así como algunos exclusivos hoteles y comercios. Al igual que otras plazas del mundo, como las de las capitales rusa y china, el Zócalo se destinó a las manifestaciones masivas organizadas por el partido hegemónico que gobernó a México por más de siete décadas. Convertido en símbolo del poder central, no acogió sino las ceremonias oficiales hasta 1968, cuando la oposición disputó cada vez más exitosamente este espacio y se volvió entonces instrumento de calibre político, donde se evalúa la capacidad de movilización de los partidos.

En 1997, al arribo del Partido de la Revolución Democrática se decidió recuperar el uso colectivo de diversos espacios públicos para contrarrestar la inseguridad e impulsar la sociabilidad urbana. El Zócalo capitalino volvió a atraer visitantes que pudieron disfrutar de una oferta cultural variada y gratuita: exhibición de películas, espectáculos masivos (conciertos, danza, poesía, teatro), concursos de ajedrez, fiestas populares, etc. La variedad de artistas presentados - Madredeus, Cesarea Evora, Manu Chao, Pablo Milanés, Charlie García, entre otros - rompió el carácter "popular" de los eventos organizados por el gobierno de la ciudad, convirtiéndolos en actos multiclasistas de convivencia democrática, verdaderamente excepcionales en una ciudad crecientemente fragmentada (NIVÓN; MANTECÓN, 2002). 
Segundo estudio de caso: ¿̇n museo fallido? La mitificación del pasado prehispánico en el Museo del Templo Mayor

Aquel 28 de febrero de 1978 sentí pleno y redondo el poder: podía, por mi voluntad, transformar la realidad que encubría raíces fundamentales de mi México, precisamente en el centro original de su historia... Poner, junto a la plaza donde está el templo del crucificado, el de la descuartizada ${ }^{15}$. Abrir el espacio de nuestra conciencia de Nación excepcional.

José López Portillo/Presidente de México (1976-1982).

En la jerarquía del patrimonio que comparten con otros sectores sociales los habitantes del Centro Histórico, las producciones culturales prehispánicas son más valoradas que las producidas en el período colonial. Al entrevistarlos y exponerles el caso de las excavaciones del Templo Mayor, les pregunté su parecer acerca de la demolición de una manzana completa de edificios coloniales realizada por el gobierno a finales de los años setenta del siglo XX para poner al descubierto los restos de la pirámide que formaba parte del recinto sagrado que ocupaba el centro de la capital azteca antes de su destrucción por los españoles - y el 70\% estuvo de acuerdo, argumentando que vale la pena evidenciar "la historia más antigua", que "es más mexicano lo arqueológico" y que el deterioro era "inevitable". Se vislumbran las huellas del proyecto nacionalista que finalmente triunfó hace un siglo, cuando vemos que el aprecio por lo colonial fue manifestado expresamente por apenas el 3,1\%.

La noción de patrimonio se forió en México al mismo tiempo que el nacionalismo. Al consumarse la conquista de México, todo lo relacionado con el mundo prehispánico fue severamente atacado, pero a finales del siglo XVIII las manifestaciones independentistas propiciaron que las miradas se volvieran hacia el México precortesiano que fue convertido en antecedente glorioso y fundamento histórico del nuevo Estado. A partir de entonces, la cultura mexica ocupó un lugar central en las políticas oficiales de definición de la identidad nacional, que siempre la presentaron monumental y grandiosa.

En un estudio que realicé sobre los públicos del Museo del Templo Mayor (MTM) en 1990 (MANTECÓN, 1993)'16 encontré que alrededor de dos terceras partes de los visitantes entrevistados mostró una imagen idealizada de los mexicas, no obstante que entre los objetivos explícitos del guión museográfico estaba su desmitificación. Al analizar las respuestas a la pregunta sobre si les hubiera gustado vivir en el tiempo de los mexicas, resultó significativo que la identificación con este grupo prehispánico no surgiera de un conocimiento objetivo de éste, sino muchas veces del desconocimiento. La apropiación del patrimonio mexica está mediada no sólo por el nivel educativo o de ingresos: encuentra
15. El presidente se refiere a la Coyolxauhqui, un monolito circular de cantera, perteneciente a la cultura mexica y que representa a la diosa de la luna en forma de mujer descuartizada. Los restos del Templo Mayor se encuentran al lado de la Catedral Metropolitana, de ahí la referencia de López Portillo al "crucificado".

16. La investigación sobre el Museo del Templo Mayor formó parte del proyecto general Políticas, necesidades y consumo cultural en la ciudad de México, coordinado por Néstor García Canclini. Para el estudio utilicé una combinación de técnicas cualitativas y cuantitativas de investigación: se muestran así datos provenientes de fuentes bibliográficas y hemerográficas, revisión documental del archivo del MTM, entrevistas, análisis estadístico de encuestas y observación directa. 
sus raíces en la vida cotidiana del público, en sus necesidades inmediatas. Sobre el mito de los mexicas se proyectan así expectativas, frustraciones, sueños.

La empresa desmitificadora es emprendida por el MTM fundamentalmente a través de dos vías: la distribución de las piezas dentro de un ordenamiento que busca contextualizarlas launque no siempre se logra, se trata de presentar en cada sala lotes de objetos relacionados con el tema respectivo) y por medio de las cédulas introductorias a cada sala. La narración que proponen, sin embargo, debe competir con otra, la vivencial (uno la va armando con la experiencia de la teatralidad), que es acentuada a través de la oscuridad dominante que envuelve sorpresivamente al visitante. La luz está dirigida hacia los objetos y las cédulas que se encuentran grabadas sobre vidrio biselado. En varias de las salas, se puede considerar que éstas fueron creadas fundamentalmente para ser admiradas como tallas: leerlas requiere un gran esfuerzo dada la escasa iluminación y el material transparente del que están hechas.

Es tal el peso de la teatralidad que el visitante se ve impulsado a vivenciar la admirable puesta en escena, más que a reflexionar sobre los contenidos ofrecidos, que pierden peso ante el sentido general que produce el manejo de los objetos y los espacios. Hay una desproporción entre los medios utilizados para la transmisión del mensaje: como la desmitificación se basa preponderantemente en las cédulas y la organización de algunas salas, encuentra grandes dificultades para ser efectiva. Las cédulas con perspectiva crítica resultan inefectivas frente a la museografía monumental; ésta le permite al Estado buscar su legitimación a través de la teatralización de su unidad con el pasado prehispánico. El peso de dicha concepción en el museo se ve reforzado, además, por su localización justo al lado del Palacio Nacional, la Catedral Metropolitana y el Zócalo, pilares fundamentales para la identidad nacional. Sin embargo, no podemos atribuir al contacto con el Museo la responsabilidad exclusiva de la mitificación de los mexicas. Dicha visión, que es la base para la construcción de nuestra "conciencia de Nación excepcional", como lo manifestó tan diáfanamente José López Portillo, corresponde a una particular idea de la nacionalidad mexicana, hegemonizada también a través de la escuela y los medios de comunicación.

Busqué ir más allá en el análisis de la relación emisión-recepción, sondeando hasta dónde se da, por parte del público, un proceso activo de apropiación diferenciada de las propuestas del MTM, dependiendo de su edad, nivel de escolaridad, origen social, hábitos de consumo, etc. Si bien es cierto que la oferta del museo se realiza a la manera de un texto, a través del cual se restringen y/o inducen las posibilidades de lectura, este texto no es omnipotente: no podemos deducir de la caracterización de lo que se ofrece lo que el público recibe. Esto se debe fundamentalmente a dos factores: por un lado, la oferta de todo museo es múltiple y compleja, debido a que existen diferentes niveles de 
emisión del mensaje (las cédulas escritas, la colocación de los objetos, su iluminación, la organización de las salas, las visitas guiadas, etc.). Por otra parte, la emisión-recepción se ve también mediada por la heterogeneidad del público, que en el caso del MTM se diferencia a grandes rasgos en dos grupos: el que acude el fin de semana y el de entre semana.

En general, mientras entre semana acuden visitantes que se acercan más al perfil clásico del público de museos (estudiantes y empleados, que asisten preferentemente solos o en pequeños grupos), el público del domingo se encuentra más diversificado (está constituido por aquéllos que van a pasear al Zócalo y sienten curiosidad por conocer el museo ya que lo tienen enfrente): tiende a tener una menor escolaridad que el de entre semana, ocupaciones diversas, menores ingresos y la cantidad de familias con niños pequeños aumenta considerablemente, por lo que las visitas son menos detenidas y la apreciación más superficial. Corrobora lo anterior el hecho de que el fin de semana menos de la tercera parte de los asistentes leyó la mayoría de las cédulas, frente al público de entre semana, del cual más de la mitad las leyó. Al observar el tiempo de estancia en cada sala, encontré que permanecían un mayor tiempo en ellas cuando había información verbal disponible (por parte de custodios o guías). En el mismo sentido, identificamos una tendencia hacia una actitud más crítica hacia los mexicas en los que asisten entre semana y más idealizadora el fin de semana.

Las posibilidades de tomar en cuenta a los públicos diversos que concurren al museo se incrementan en la medida en que se explicite y cuestione el público implícito del MTM y todos los dispositivos adecuados exclusivamente a él. Este público implícito en cualquier oferta cultural convoca a los elegidos, esto es, crea sus propias audiencias, de diversas maneras. Se trata de una oferta de comunicación que busca su recepción adecuada, ideal. Wolfgang Iser lo llamó lector implícito y Umberto Eco, lector modelo. De la misma manera que cada texto contiene ya a un lector, que no es un lector real, sino un constructo que influye en el modo de lectura y en el efecto del texto en los lectores, los dispositivos de información y comunicación de los museos contienen implicaciones, presuposiciones, intenciones y estrategias integradas en ellos mismos y en la manera en la que se despliegan en los espacios del museo. No son igualmente bienvenidos los otros públicos, esto es, aquellos que no leen las cédulas, que van en familia, que hacen una visita más rápida y que cuentan con mucho menor capital cultural que los interlocutores "ideales" del MTM. El cuestionamiento del público implícito en el museo abre las puertas a políticas educativas, de difusión y promoción diferenciadas, de acuerdo a las necesidades y demandas de públicos también diferenciados. 
17. BOURDIEU; DARBE, 1987, p. 201
Comentarios finales: ¿Para qué estudiar a los públicos?

\begin{abstract}
Si el amor al arte es la señal de la elección que separa como infranqueable a los elegidos de los no elegidos, se comprende que los museos traicionen, en los menores detalles de su morfología y de su organización, su verdadera función que es la de reforzar en unos el sentimiento de pertenencia y en los otros el sentimiento de exclusión.
\end{abstract}

Pierre Bourdieu y Alain Darbel ${ }^{17}$

Aquéllos que logran llegar a los museos y constituirse en sus públicos son los vencedores de una larga carrera de obstáculos: han recorrido la distancia geográfica que separa estos espacios culturales, alejados del ámbito cotidiano de la mayoría de los habitantes de la ciudad; pagaron su traslado y el precio del boleto, en los casos en los que no podían gozar de alguna exención; adquirieron, en su familia y/o en la escuela, un determinado capital cultural que les permite acceder, en diversas medidas, a lo que ofrece el museo; recorrieron la distancia simbólica que aleja a muchos del patrimonio sacralizado, producto de su construcción social jerarquizada; dejaron el abrigo de sus hogares, venciendo la poderosa atracción que ejerce la oferta mediática. Una vez en el museo, es posible que los que no forman parte del público implícito deban enfrentar barreras en los dispositivos de comunicación e información, aún en el trato que les brinda el personal de custodia. Muchos no llegan y de hecho, ni lo intentan. No son, ni se sienten convidados.

Quién arriba o no a los museos, durante mucho tiempo no fue objeto de una atención prioritaria por parte de éstos: lo relevante era acrecentar, proteger e investigar sus acervos, así como ponerlos en escena de acuerdo a criterios decididos sin consultar a los concurrentes. He relatado la multiplicidad de factores que han impulsado el cambio de esta situación y que formulan nuevos retos a los museos, entre ellos el de atraer nuevos públicos y generar recursos, pero también el de reconceptualizar su función como instituciones incorporadas al desarrollo económico y cultural de la sociedad contemporánea.

Buscando asumir estos retos, algunos museos han intentado tornarse en lugares más acogedores, desarrollando sistemas interactivos, espacios lúdicos, talleres y actividades educativas vinculadas a las exposiciones. Las estrategias ensayadas para captar nuevos públicos abarcan desde la mejora de la visibilidad de sus anuncios y carteleras, promoción en los medios, la realización de actividades paralelas: conferencias, festivales, ciclos de cine, conciertos, etc., hasta la remodelación de la tienda y la cafetería. Otros también se han preocupado por llevar su oferta a los que no se acercan, a través de exposiciones fuera de los recintos tradicionales (en el Sistema de Transporte Colectivo Metro, sobre las rejas de Chapultepec, incluso en las cárceles), o elaborando páginas de Internet donde se muestran las colecciones de manera virtual a visitantes de todo el planeta. 
La vinculación de los museos con las necesidades de su entorno pasa por el necesario cuestionamiento del monólogo que ha guiado su funcionamiento. Como ha señalado Silvia Singer, presidenta del Consejo Internacional de Museos (ICOM) en México,

el siguiente desafío de los museos es, además de estudiar y manejar su colección, conocer de manera muy especial a sus públicos, en plural. Esto es un cambio de paradigma muy importante, porque hasta hace algún tiempo se hablaba de un público en general o de públicos especializados; pero los visitantes deben conceptualizarse en muchos más grupos, todos ellos con necesidades y objetivos distintos ${ }^{18}$.

Lejos de haber un perfil homogéneo de asistencia, podemos reconocer que cada museo tiene una personalidad propia que atrae a una gama particular de visitantes con intereses específicos, que deben ser identificados para poder ser atendidos.

Resulta preocupante que en lugar de considerar a los visitantes como punto de partida para el diseño de las actividades de los museos, se continúe operando estas instituciones a partir de las directrices de los dirigentes, sin considerar las expectativas y necesidades de sus heterogéneos públicos. El impacto de los estudios de público ha sido aún limitado sobre el diseño y evaluación de políticas culturales en México. En ocasiones, los estudios se realizan y se reciben por una estructura burocrática que no está diseñada para transformarse en función de lo que plantean, lo cual dificulta el que las investigaciones sobre los públicos tengan el impacto deseado. En otras, la realización de encuestas es producto de una mera búsqueda de legitimación por parte de autoridades gubernamentales (muchas veces utilizadas como lo llegan a hacer los partidos políticos, como mera propaganda).

Hay diversas áreas en las que los estudios de audiencias pueden presentarse como especialmente sugerentes y que están prácticamente inexploradas. Una de ellas es la formación de públicos. Si tomamos en cuenta que los públicos no nacen, sino se hacen, esto es, que son constantemente formados y deformados por la familia, la escuela, los medios, las ofertas culturales comerciales y no comerciales, entre otros agentes que influyen - con diferentes capacidades y recursos - en las maneras cómo se acercan o se alejan de las experiencias de consumo cultural, las políticas de formación de públicos pueden ser repensadas a la luz de las investigaciones realizadas. En general, las instituciones gubernamentales encargadas de la promoción y la difusión cultural, han limitado la formación de públicos a multiplicar la oferta y la publicidad, pero todo esto no se ha transformado en experiencias reales de formación de la capacidad de disfrute del arte. Ante la inefectividad estatal, niños, jóvenes y adultos se forman como públicos fundamentalmente por la televisión y la oferta comercial.

A través de los estudios de público se pueden detectar necesidades comunes de grupos diversos. Aproximadamente la mitad de los museos de la ciudad de México están ubicados en el Centro Histórico y ante la ausencia de un tratamiento integral a la problemática común que enfrentan en esta zona, el 
ambulantaje, la inseguridad y la delincuencia han originado una reducción de la afluencia de visitantes (CASTRO, 2000, p. 12). Por la concentración de museos, no sería difícil crear redes de vigilancia que garanticen la seguridad de los visitantes, implementar acciones conjuntas de regeneración urbana para mejorar la imagen del entorno de los museos, así como apoyar su vinculación con la población circundante, con los habitantes de las colonias periféricas y con el turismo.

El reto de la inclusión en los museos pareciera incuestionable. Sin embargo, los impulsos que lo motivan pueden ser contrapuestos: por una parte, el de democratizar el acceso a la cultura y, por la otra, el de realizar una mejor mercantilización de estos espacios. La clave para diferenciarlos pareciera residir en cómo se convoca a los públicos: como clientes a complacer o como ciudadanos con derechos comunicacionales y culturales. Como ha señalado Graciela Schmilchuk (2004, p.59):

[...] el reto no es aumentar audiencias, sino acrecentar la comprensión de los mecanismos de exclusión y las fuerzas actuantes en la institución y en el campo cultural, con el fin de poder intervenir en ellos; entablar diálogos cada vez más abiertos con sectores interesados y participantes $y$, de acuerdo con ello, de este modo brindar una gama variada y compleja de servicios adecuados, en relación con las colecciones u objetivos del museo y con las características socioculturales de los públicos efectivos y potenciales. El reto es que la relación museo-sociedad sea el verdadero soporte y fuerza de la institución.

No se trata pues de simplificar o espectacularizar los recursos museográficos para hacer más rentable la institución, sino de atraer y atender a la mayor diversidad posible de públicos, reconociendo que el objetivo principal es el combate a la inequidad en el acceso a la cultura.

\section{REFERENCIAS}

APPADURAI,A.(Ed.). La vida social de las cosas. Perspectiva cultural de las mercancías. México: Grijalbo/Consejo Nacional para la Cultura y las Artes, 1991.

AURA,A. La cultura como la dimensión central del desarrollo. In: I CONGRESO INTERNACIONAL CULTURA Y DESARROLLO, La Habana, junio de 1999.

BORDIEU, P.; DARBEL,A. L'amour de l'art. Paris: Minuit, 1987.

CANCLINI, N. G. ; PICCINI, M. Culturas de la ciudad de México: símbolos colectivos y usos del espacio urbano. In: CANCLINI, N. G. (Coord.). El consumo cultural en México. México: Consejo Nacional para la Cultura y las Artes, 1993.

CANCLINI, N. G. El consumo cultural y su estudio en México: una propuesta teórica. In: El consumo cultural en México. México: Consejo Nacional para la Cultura y las Artes, 1993.p. $15-42$. 
CANCLINI, N. G. Consumidores y ciudadanos. México: Grijalbo, 1995.

CASTRO,A. H. Los museos de la ciudad de México. México, 2000 (sin publicar).

CIMET, E. et al. El público como propuesta: cuatro estudios sociológicos en museos de arte. México: Instituto Nacional de Bellas Artes, 1987.

CONSEJO NACIONAL PARA LA CULTURA Y LAS ARTES. Atlas de infraestructura cultural de México. México: Conaculta, 2003.

COORDINACIÓN DE ASESORES DE IGNACIOTOSCANO. Informe sobre los Museos del Instituto Nacional de Bellas Artes, 2001 (sin publicar).

ECO, U. Lector in fabula. Barcelona: Lumen, 1981.

EDER, R. et al. El público de arte en México: los espectadores de la exposición Hammer. Plural, México, v. IV, n. 70, julio, p. 12-23, 1977.

GONZÁlEZ, J.; CHAVEZ, M. G. La cultura en México. México: Consejo Nacional para la Cultura y las Artes/Universidad de Colima, 1996.

INSTITUTO NACIONAL DE ESTADÍSTICA, GEOGRAFÍA E INFORMÁTICA. Cuaderno Estadístico de la zona metropolitana de la ciudad de México. México: INEGI/Gobierno del Distrito Federal/Gobierno del Estado de México, 2002.

ISER, W. El acto de la lectura. Consideraciones previas sobre una teoría del efecto estético. In: DIETRICH, R. (Comp.). En busca del texto. Teoría de la recepción literaria. México: UNAM, 1993.

MANTECÓN,A. R. La puesta en escena del patrimonio mexica y su apropiación por los públicos del Museo del Templo Mayor. In: CANCLINI, N. G. El consumo cultural en México. México: Consejo Nacional para la Cultura y las Artes, 1993.

. La monumentalización del patrimonio: políticas de conservación y representaciones del espacio en el Centro Histórico. In: CANCLINI, N. G. (Coord.). Cultura y comunicación en la ciudad de México. México: Grijalbo/Universidad Autónoma Metropolitana-Iztapalapa, 1998.

. Los estudios sobre consumo cultural en México. En: MATO, D. (Coord.). Estudios y otras prácticas intelectuales latinoamericanas en cultura y poder. Caracas: CLACSO/Facultad de Ciencias Económicas y Sociales de la Universidad Central de Venezuela, 2002.

MESSMACHER, M. México: megalópolis. México: SEP/Foro 2000, 1987.

MONZÓN,A. Bases para incrementar el público que visita el Museo Nacional de Antropología. Anales del Instituto Nacional de Antropología e Historia. México, t. VI, $2^{\text {a }}$ parte, 1952.

NIVÓN, E.; MANTECÓN.A. R. México: la política cultural del gobierno del Distrito Federal $1997-$ 2000. Notas para un balance. In: LACARRIEU, M.; ÁLVAREZ, M. (Comp.). La (indi)gestión cultural. Una cartografía de los procesos culturales contemporáneos. Buenos Aires: Ediciones Ciccus-La Crujía, Colección Signo. Comunicación y Sociedad, 2002. 
PETIT,M.Nuevos acercamientos a los jóvenes y a la lectura. México:Fondo de Cultura Económica, 1999.

RENOVACION HABITACIONAL POPULAR. Memoria de la reconstrucción. México: RHP, 1988.

SCHMILCHUK, G. Museos: comunicación y educación. Antología comentada. México: Instituto Nacional de Bellas Artes/Dirección de Investigación y Documentación de las Artes/Cenidiap, 1987.

.Venturas y desventuras de los estudios de público. Cuicuilco, México, Nueva época, v. 3, n. 7, mayo-ago., p. 31-57, 1996.

. El público: clientes o ciudadanos con derechos. In: CONACULTA (Ed.). La voluntad de mostrar, el ingenio de ver. Museos de México y del mundo. México - Consejo Nacional para la Cultura y las Artes/INAH/INBA, México, D. F., v. 1, n. 1, p. 58-59, primavera de 2004.

SECRETARÍA DE TURISMO DEL GOBIERNO DEL DISTRITO FEDERAL. Agenda estadística de turismo. México: Gobierno del Distrito Federal, 2001.

SUNKEL, G. (Coord.). El consumo cultural en América Latina. Santafé de Bogotá: Convenio Andrés Bello, 1999.

WITKER, R. Los museos. México: Consejo Nacional para la Cultura y las Artes, Colección Tercer Milenio, 2001.

ZWINGLE, E. Ciudades. National Geographic, México, p. 70-99, 2002.

Artigo apresentado em 05/2005. Aprovado em 09/2005. 